\title{
Effects of biochar on nitrogen and phosphorus retention in the coastal wetland soil of the Yellow River Delta, China
}

\author{
Jing Miao ${ }^{1,2}$, Xiaotong $\mathrm{Li}^{1,2}$, Xiao Wang ${ }^{1,2^{*}}$ \\ ${ }^{1}$ Institute of Coastal Environmental Pollution Control, Key Laboratory of Marine Environment and Ecology, Ministry of Education, \\ Ocean University of China, Qingdao 266100, China \\ ${ }^{2}$ College of Environmental Science and Engineering, Ocean University of China, Qingdao 266100, China
}

\begin{abstract}
Nutrient deficiency (nitrogen, phosphorus) strongly limited the productivity of the degraded coastal soils in the Yellow River Delta. Biochar (BC) is a kind of porous carbonaceous material. It has raised wide interests because of their multiple benefits in soil improvement. The effects of biochar on the retention of nitrogen and phosphorus varied with the types of biochar and soil properties. In this study, a maize straw derived BC was applied into a coastal salt-affected soil collected from the Yellow River Delta to investigate the response of soil nutrient using a three-month cultivating experiment with the simulated rainfall. The results showed that the addition of biochar reduced the content of $\mathrm{NH}_{4}{ }^{+}-\mathrm{N}$ and $\mathrm{NO}_{3}{ }^{-}-\mathrm{N}$ in all-depth soil by $8.1-27.0 \%$ and $25.3-51.9 \%$, respectively. The content of TP in $0-30 \mathrm{~cm}$ soil was significantly increased, while it had no significant effect on the content of TP in $30-60 \mathrm{~cm}$ soil. These findings would provide theoretical basis and technical support for developing feasible technologies for remediating degraded coastal wetland soil.
\end{abstract}

\section{Introduction}

The Yellow River Delta, a typical coastal wetland located in the warm-temperate zone of China, is the youngest and largest coastal wetland ecosystem [1]. The dominant soil with high-salt stress (sodium, $\mathrm{Na}^{+}$) and nutrient deficiencies (e.g., soil organic carbon (SOC), nitrogen (N), and phosphorus (P)), have degraded severely, thus threatening soil health and productivity [2]. Therefore, how to remediate and maintain a sustainable utilization of these soils has become an urgent task. But several existing technologies (e.g., washing, phytoremediationa and chemical restoration) for remediating the coastal soil have been limited due to their drawbacks (e.g., high costs, or secondary pollution) [3]. Therefore, a modified technology with cost-effective and sustainable benefits is urgently needed for improving soil quality and restoring vegetation in coastal soil.

Biochar (BC), a highly aromatized carbon-rich material, is produced from the pyrolysis/carbonization of plant-or animal-based biomass, widely used as a soil amendment for improving soil quality and carbon sequestration [4]. Biochar addition into soils could improve soil quality (e.g., bulk density, porosity, water and nutrient retention) and altering microbial community structure [5]. However, biochar-mediated nitrogen and phosphorus retention does not always have positive effects, it depends on the specific types of soil and biochar, as well as their interactions [6]. Previous studies have documented reduced leaching from soil amended with biochar. Zheng et al. [7] reported that biochar could improve nutrient retention and efficiency by the higher sorption capacity of biochar and water retention.

The application of biochars, especially those with low $\mathrm{P}$ content $\left(<1000 \mathrm{mg} \mathrm{kg}^{-1}\right)$, to soils has reportedly increased $\mathrm{P}$ retention in soil, thereby alleviating the leaching of $\mathrm{P}$ from soil to surface water or groundwater [8], because of biochar can (1) directly adsorb soil P [9, 10], (2) decrease water loss from soil, and (3) promote $\mathrm{P}$ uptake by plants [11]. Therefore, it is reasonable to hypothesize that biochar addition may contribute to increase nitrogen and phosphorus retention in soil. The objective of this laboratory study was to investigate if maize straw derived biochar could increase the retention of nitrogen and phosphorus in coastal salt-affected soil.

\section{Materials and methods}

\subsection{Soil and Biochar}

The coastal soil samples were collected from the Yellow River Delta Wetland Nature Reserve $\left(37^{\circ} 51^{\prime} \mathrm{N}, 119^{\circ} 00^{\prime} \mathrm{E}\right)$, located in the Yellow River Delta, China. Randomly selected top-soil samples were taken at 0-20 cm depth and sub-soil samples were taken at 20-60 cm depth, air-dried, and ground to pass a 2-mm sieve and thoroughly homogenized. Soil pH, electrical conductivity (EC), CEC, $\mathrm{NO}_{3}{ }^{-}-\mathrm{N}, \mathrm{NH}_{4}{ }^{+}-\mathrm{N}$, and TP were measured [12]. The main properties of soil are presented in Table 1.

The biochar was produced from maize straw at $550^{\circ} \mathrm{C}$ for $3 \mathrm{~h}$ and then ground to pass a 2-mm sieve and thoroughly homogenized $[13,14]$. Total $\mathrm{C}$ and N, pH, ash

\footnotetext{
* Corresponding author: wangxiao5120@ouc.edu.cn
} 
content, $\mathrm{K}^{+}, \mathrm{Na}^{+}, \mathrm{Ca}^{2+}$ were characterized as described by Zheng et al. [7]. The main properties of biochar is presented in Table 2 .

Table 1. The main properties of the soil

\begin{tabular}{|c|c|c|c|c|c|c|c|}
\hline & $\mathrm{pH}$ & $\begin{array}{c}\mathrm{EC} \\
\left(\mathrm{mS} \mathrm{cm}^{-1}\right)\end{array}$ & $\begin{array}{c}\mathrm{Ex}-\mathrm{Na} \\
\left(\mathrm{cmol} \mathrm{kg}^{-1}\right)\end{array}$ & $\begin{array}{c}\text { CEC } \\
\left(\mathrm{cmol} \mathrm{kg}^{-1}\right)\end{array}$ & $\begin{array}{c}\mathrm{NH}_{4}^{+}-\mathrm{N} \\
\left(\mathrm{mg} \mathrm{kg}^{-1}\right)\end{array}$ & $\begin{array}{c}\mathrm{NO}_{3}{ }^{-} \mathrm{N} \\
\left(\mathrm{mg} \mathrm{kg}^{-1}\right)\end{array}$ & $\begin{array}{c}\mathrm{TP} \\
\left(\mathrm{mg} \mathrm{kg}^{-1}\right)\end{array}$ \\
\hline $\begin{array}{c}\text { Surface } \\
\text { soil }\end{array}$ & $8.46 \pm 0.01$ & $11.78 \pm 0.54$ & $12.38 \pm 0.09$ & $16.56 \pm 0.12$ & $2.98 \pm 0.89$ & $11.93 \pm 0.89$ & $500.14 \pm 7.66$ \\
\hline Subsoil & $8.32 \pm 0.03$ & $9.11 \pm 0.14$ & $11.43 \pm 0.08$ & $14.70 \pm 0.11$ & $5.34 \pm 0.11$ & $12.67 \pm 0.94$ & $441.49 \pm 6.76$ \\
\hline & & $\mathrm{TC}$ & TN & Ash & $\mathrm{K}^{+}$ & $\mathrm{Na}^{+}$ & $\mathrm{Ca}^{2+}$ \\
\hline & $\mathrm{pH}$ & $(\%)$ & $(\%)$ & $(\%)$ & $\left(\mathrm{mg} \mathrm{kg}^{-1}\right)$ & $\left(\mathrm{mg} \mathrm{kg}^{-1}\right)$ & $\left(\mathrm{mg} \mathrm{kg}^{-1}\right)$ \\
\hline Biochar & $8.32 \pm 0.03$ & $68.78 \pm 0.05$ & $0.67 \pm 0.01$ & $14.53 \pm 0.06$ & $21985 \pm 197$ & $620.00 \pm 5.58$ & $504.40 \pm 4.54$ \\
\hline
\end{tabular}

\subsection{Soil Column Incubation}

Free-draining soil columns were constructed with organic glass tubes (length, $7 \mathrm{~cm}$; tube internal diameter, $6 \mathrm{~cm}$ ) and fit with silica sand (high, $3 \mathrm{~cm}$ ) at the tops and bottoms., there is a $5 \mathrm{~mm}$ hole at the bottom of each tube. The prepared biochar was incorporated into the selected soil at rates of $3 \%(\mathrm{w} / \mathrm{w})$, referred to as $3 \% \mathrm{BC}$. The saltaffected soil without biochar added was used as a blank control and was recorded as CK. There were 2 treatments in total, with 3 replicates for each treatment, and a total of 6 soil columns. After the soil column is loaded according to the above treatment, ultrapure water is added to collect the leachate, and the leachate is backfilled several times to keep the soil nutrients and make the soil reach the field capacity. The experiment was conducted at $25 \pm 1^{\circ} \mathrm{C}$ for 3 months, during which $200 \mathrm{ml}$ ultrapure water was slowly dropped into a bottle infusion set to simulate precipitation for leaching.

When the experiment was finished, divided the soil into 6 layers $\left(10 \mathrm{~cm}\right.$ each). $\mathrm{NH}_{4}{ }^{+}-\mathrm{N}$ and $\mathrm{NO}_{3}{ }^{-}-\mathrm{N}$ contents of the soil were determined using spectrophotometric method with indophenol blue reagent and phenol disulfonic acid, respectively. Contents of TP in soil was determined using the molybdate-ascorbic acid method, after digestion of soil with $\mathrm{H}_{2} \mathrm{SO}_{4}-\mathrm{HClO}_{4}$.

\subsection{Statistical analysis}

All results were expressed as the mean values $(n=3)$. Error bars presented in the results represent the standard deviation. The significance of the various parameters was tested by one-way analysis of variance (ANOVA) using Duncan's multiple range test $(P<0.05)$ by Statistical Product and Service Solutions software (SPSS 20.0).

\section{Results and discussion}

\subsection{Effecs of biochar on $\mathrm{NH}_{4}{ }^{+}-\mathrm{N}$ and $\mathrm{NO}_{3}{ }^{-}-\mathrm{N}$ in soil}

The $\mathrm{NH}_{4}{ }^{+}-\mathrm{N}$ content in the soil treated with biochar was shown in Figure 1. After the culturing, the $\mathrm{NH}_{4}{ }^{+}-\mathrm{N}$ content in all depth reduced by $6.06-17.19 \%$ in $\mathrm{CK}$ treatment; the $\mathrm{NH}_{4}{ }^{+}-\mathrm{N}$ content in all depth reduced by 8.06-26.96\% in BC treatment; Compared with CK, BC application reduced the $\mathrm{NH}_{4}{ }^{+}-\mathrm{N}$ content in all the depth of soil by $2.13-21.35 \%$. The content of $\mathrm{NH}_{4}{ }^{+}-\mathrm{N}$ in $0-30 \mathrm{~cm}$ soil were significantly reduced, but biochar addition had no significant influence on the content of $\mathrm{NH}_{4}{ }^{+}-\mathrm{N}$ in 30$60 \mathrm{~cm}$ soil. Mainly due to biochar could retain $\mathrm{NH}_{4}{ }^{+}-\mathrm{N}$ in soil through acid functional groups (e.g. carboxyl and hydroxyl) on its surface via cation exchange, it have a negative charge and adsorb $\mathrm{NH}_{4}^{+}-\mathrm{N}$ by electrostatic attraction, but fresh biochar's cation exchange capacity can be limited and depends on the feedstocks and conditions of manufacturing biochar $[7,15,16]$.

The $\mathrm{NO}_{3}{ }^{-} \mathrm{N}$ content in the soil treated with biochar was shown in Figure 2. After the culturing, the $\mathrm{NO}_{3}{ }^{-}-\mathrm{N}$ content in all depth reduced by $5.77-32.69 \%$ in $\mathrm{CK}$ treatment; the $\mathrm{NO}_{3}^{-}-\mathrm{N}$ content in all depth reduced by 25.33-51.92\% in BC treatment; Compared with CK, BC application reduced the $\mathrm{NO}_{3}{ }^{-}-\mathrm{N}$ content in all the depth of soil by $11.43-45.65 \%$. The contents of $\mathrm{NO}_{3}{ }^{-}-\mathrm{N}$ in all the depth of soil were significantly reduced $(P<0.05)$. Biochar may absorb $\mathrm{NO}_{3}{ }^{-}$from aqueous solution [7], which may be one of the reasons for the reduction of $\mathrm{NO}_{3}{ }^{-}$ $-\mathrm{N}$ content in soil. Study show that $\mathrm{NO}_{3}{ }^{-}-\mathrm{N}$ adsorption by biochar is weak because biochar carries greater negative surface charges than positive surface charges [17]. However, the existence of base functional groups including chromenes, ketones and pyrones on biochar can facilitate $\mathrm{NO}_{3}^{-}-\mathrm{N}$ adsorption to biochar. $\mathrm{NO}_{3}^{-}-\mathrm{N}$ adsorption is also possible via unconventional $\mathrm{H}$-bonding between ions and the biochar surface [18]. 


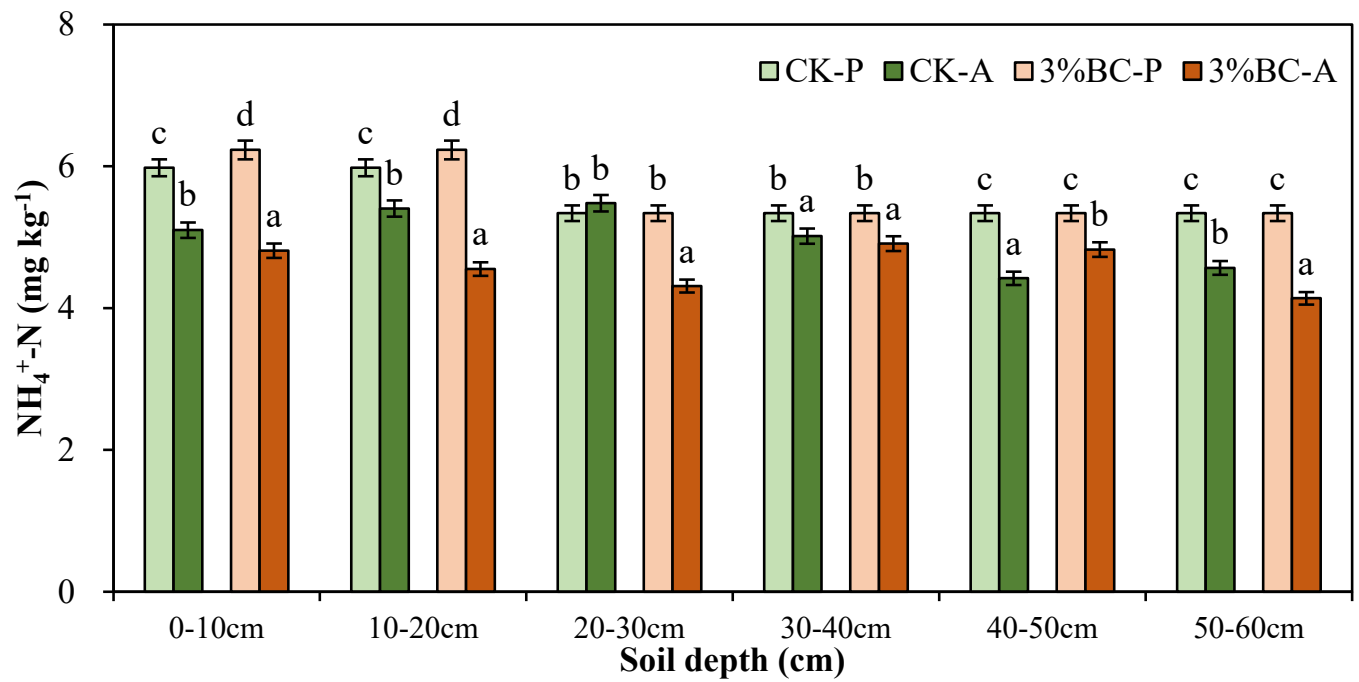

Figure 1. Effect of adding biochar on the content of $\mathrm{NH}_{4}{ }^{+}-\mathrm{N}$ in soil.

$\mathrm{CK}$ and $3 \% \mathrm{BC}$ indicated that the soil was amended with biochar at the rates of 0 and $3 \%$, respectively. The $\mathrm{P}$ and $\mathrm{A}$ indicated prior to the leaching and after to the leaching. which was analysed by Duncan's multiple range test $(P<0.05)$ using SPSS 20.0.

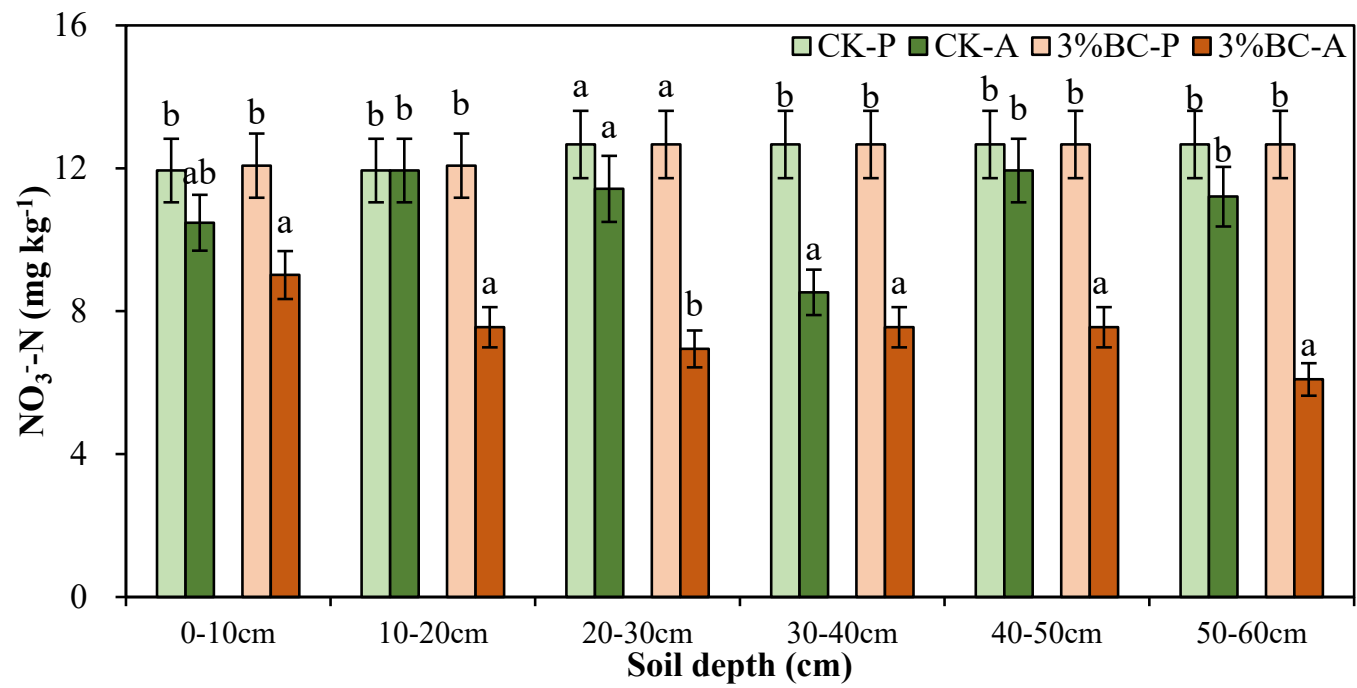

Figure 2. Effect of adding biochar on the content of $\mathrm{NO}_{3}^{-}-\mathrm{N}$ in soil.

$\mathrm{CK}$ and $3 \% \mathrm{BC}$ indicated that the soil was amended with biochar at the rates of 0 and $3 \%$, respectively. The $\mathrm{P}$ and $\mathrm{A}$ indicated prior to the leaching and after to the leaching. which was analysed by Duncan's multiple range test $(P<0.05)$ using SPSS 20.0.

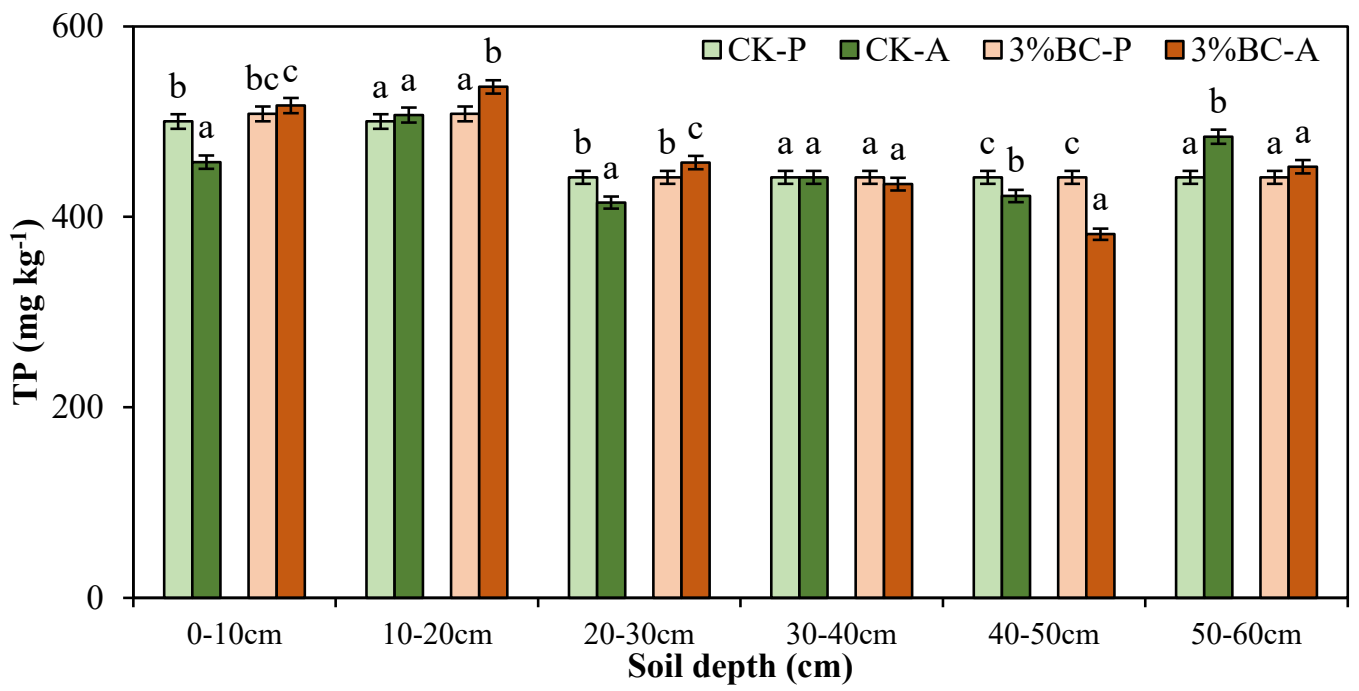

Figure 3. Effect of adding biochar on the content of TP in soil.

$\mathrm{CK}$ and $3 \% \mathrm{BC}$ indicated that the soil was amended with biochar at the rates of 0 and $3 \%$, respectively. The $\mathrm{P}$ and $\mathrm{A}$ indicated prior to the leaching and after to the leaching. which was analysed by Duncan's multiple range test $(P<0.05)$ using SPSS 20.0. 


\subsection{Effects of biochar on TP in soil}

The TP content in the soil treated with biochar was shown in Figure 3. Compared with $\mathrm{CK}$, the $\mathrm{BC}$ application significantly increased the content of TP in $0-30 \mathrm{~cm}$ soil by $5.83-12.99 \%(P<0.05)$, but the content of TP in $30-$ $60 \mathrm{~cm}$ soil was reduced by $1.62-9.51 \%$. In this experiment, the addition of biochar had no significant effect on the content of total phosphorus in $30-60 \mathrm{~cm}$ soil $(P>0.05)$. Vanita Sachdeva et al. [19] reported wood-based biochars could reduce $\mathrm{P}$ loss in surface runoff by increasing water infiltration or by improving soil stability. Lu Yang et al. [20] reviewed some possible mechanisms by which biochar may directly or indirectly influence the components of the $\mathrm{P}$ cycle. Biochar contains a large amount of P; thus, direct release of soluble $\mathrm{P}$ may be necessary to enhance $\mathrm{P}$ availability. In addition, biochar chould also directly adsorb cations such as $\mathrm{Al}^{3+}, \mathrm{Fe}^{3+}$ and $\mathrm{Ca}^{2+}$, resulting in delayed $\mathrm{P}$ adsorption or precipitation in soil, thus enhance $\mathrm{P}$ cycling and bioavailability.

\section{Conclusions}

The results showed that the addition of biochar significantly increased the content of $\mathrm{NH}_{4}{ }^{+}-\mathrm{N}$ and $\mathrm{NO}_{3}{ }^{-}-$ $\mathrm{N}$ in all depth soil, and significantly increased the content of TP in 0-30 cm soil, while it showed no influence on the content of TP in 30-60 cm soil. The reduction of $\mathrm{NH}_{4}{ }^{+}-\mathrm{N}$ and $\mathrm{NO}_{3}{ }^{-}-\mathrm{N}$ content could be attributed to electrostatic attraction, cation exchange, and $\mathrm{H}$-bonding. The increase of TP content could be attributed to biochar directly release soluble $\mathrm{P}$ into soil. These results indicated that biochar addition could increase $\mathrm{N}$ retention and $\mathrm{P}$ bioavailability in the coastal wetland soil of the Yellow River Delta, China. Thus, our findings suggested that producing the biochar materials through pyrolysis could be a feasible way to remediate the degraded coastal soil.

\section{Acknowledgments}

This study was supported by the National Natural Science Foundation of China (41573089)

\section{References}

1. D.X. Kong, C.Y. Miao, A.G. Borthwick, Q.Y. Duan, H. Liu, Q.H. Sun, A.Z. Ye, Z.H. Di, W. Gong, Journal of Hydrology, 520, 157-167 (2015).

2. A. Koch, A. Mcbratney, R. Lal, Nature, 492, 186 (2012).
3. S.C. Isabel, C.L. M, B.H. R Icela, P.V. Hector M, Geoderma, 247-248, 140-150 (2015).

4. M. Ahmad, A.U. Rajapaksha, J.E. Lim, M.W. Zhang, Chemosphere, 99, 19-33 (2014).

5. H. Zeng, X. Wang, X.X Luo, Z.Y. Wang, B.S. Xing, Science of the Total Environment, 610-611, 951-960 (2018).

6. B. Kavitha, P.V.L. Reddy, B. Kim, S.S Lee, S.K. Pandey, K.H. Kim, Journal of Environment Management, 227, 146-154 (2018).

7. H. Zheng, Z.Y. Wang, X. Deng, J. Zhao, Y. Luo, Jeff Novak, S. Herbert, B.S. Xing, Bioresource Technology, 130, 463-471 (2013).

8. Y.T. Peng, Y.Q. Sun, B.Q. Fan, S. Zhang, N.S. Bolan, Q. Chen, D.C.W. Tsang, Journal of Cleaner Production, 279,123877 (2021).

9. B. Dari, V.D. Nair, W.G. Harris, P.K.R. Nair, Lynn Sollenberger, R. Mylavarapu, Geoderma, 280, 82-87 (2016).

10. P.A. Trazzi, J.J. Leahy, M.H.B. Hayes, W. Kwapinski, Journal of Environmental Chemical Engineering, 4, 37-46 (2016).

11. G. Xu, Y. Zhang, J. Sun, H.B. Shao, Science of the Total Environment, 568, 910-915 (2016).

12. A. Alain, F. Christian, B. Pierre, (2004).

13. Z.Y. Wang, H.Y. Zong, H. Zheng, G.C. Liu, L. Chen, B.S. Xing, Chempsphere, 138, 576-583 (2015).

14. X.X. Luo, G.C. Liu, Y. Xia, L. Chen, Z.X. Jiang, H. Zheng, Z.Y. Wang, Journal of Soil and Sediments, 17, 780-789 (2017).

15. H. Zheng, Z.Y. Wang, X. Deng, S. Herbert, B.S. Xing, Geoderma, 206, 32-39 (2016).

16. T.T.N. Nguyen, C.Y. Xu, I. Tahmasbian, R.X. Che, Z.H. Xu, X.H. Zhou, H.M. Wallace, S.H. Bai, Geoderma, 288, 79-96 (2017).

17. K. Kameyama, T. Miyamoto, T. Shiono, Y. Shinogi, Journal of Environmental Quality, 41, 1131 (2012).

18. C.I. Kammann, H.P. Schmidt, N. Messerschmidt, S. Linsel, D. Steffens, C. Muller, H.W. Koyro, P. Conte, S. Joseph, Scientific Reports, 5, 11080 (2015).

19. V. Sachdeva, N. Hussain, B.R. Husk, J.K. Whalen, Geoderma, 351, 71-75 (2019).

20. L. Yang, Y.C. Wu, Y.C. Wang, W.Q. An, J. Jin, K. Sun, X.K. Wang, Science of the Total Environment, 758, 143657 (2020). 